\title{
ENSAYO SOBRE LA NULIFICACIÓN DE LA LEY EN EL CONSTITUCIONALISMO NORTEAMERICANO: TENSIONES A PARTIR DEL MONISMO Y DUALISMO DEMOCRÁTICO
}

\author{
ENSAIO SOBRE A ANULAÇÃO DA LEI NO CONSTITUCIONALISMO \\ AMERICANO: \\ TENSÕES DO MONISMO E DO DUALISMO DEMOCRÁTICO
}

\section{ESSAY ON THE LAW NULLIFICATION IN AMERICAN CONSTITUTIONALISM: TENSIONS BETWEEN DEMOCRATIC MONISM AND DUALISM}

\author{
Claudio Anibal Contreras \\ https://orcid.org/0000-0002-3304-0629 / claudiocontreras1882@gmail.com \\ Universidad Nacional del Noroeste de la Provincia de Buenos Aires.
}

Junín, Argentina.

\begin{abstract}
RESUMO
Neste ensaio, propomos analisar a relação entre o constitucionalismo norte-americano, a anulação da lei e da democracia. Onde esses nove (geralmente velhos e aristocráticos) magistrados da Suprema Corte de Justiça obtêm a autoridade para invalidar as decisões de políticos democraticamente eleitos? Como não desmascara um sistema político que só leva, naturalmente, a um governo de juízes? Embora os problemas políticos decorrentes do controle da constitucionalidade sejam tematizantes no debate constitucional local, tentaremos contribuir neste ensaio algumas ideias nascidas do atual debate norte-americano que se sobrepõem no contexto latino-americano e que contribuem para enriquecê-lo.
\end{abstract}

Palavras-chave: democracia; constitucionalismo; controle judicial; poder judiciário.

\section{ABSTRACT}

In this essay, we propose to analyze the relationship between American constitutionalism, the annulment of the law and democracy. Where do these nine (often old and aristocratic) magistrates of the Supreme Court obtain the authority to invalidate the decisions of democratically elected politicians? How does it not unmask a political system that only leads, of course, to a government of judges? Although the political problems arising from the control of constitutionality are thematizing in the local constitutional debate, we will try to contribute in this essay some ideas born of the current American debate that overlap in the Latin American context and that contribute to enrich it.

Keywords: democracy; constitutionalism; judicial control; judicial power.

\section{RESUMEN}

En el presente ensayo nos proponemos analizar la relación entre el constitucionalismo norteamericano, la nulificación de la ley y la democracia. ¿De dónde sacan esos nueve (generalmente viejos y aristocráticos) magistrados de la Corte Suprema de Justicia la autoridad para invalidar las decisiones de unos políticos democráticamente elegidos? ¿Cómo de ello no se desenmascara un sistema político que sólo lleva, naturalmente, a un gobierno de los jueces? Si bien los problemas políticos derivados del control de constitucionalidad es un tema un poco remanido en el debate constitucional local, intentaremos aportar en este ensayo algunas ideas nacidas del actual debate norteamericano que quedan solapadas en el ámbito latinoamericano y que coadyuvan a enriquecerlo.

Palabras clave: democracia; constitucionalismo; control judicial; poder judicial. 


\section{SUMÁRIO}

INTRODUCCIÓN; 1 EL VALOR DE LOS ANTECEDENTES Y LOS PRINCICIPIOS CONSTITUCIONALES; 2 EI PROBLEMA DEL ORIGEN DE LA NOCIÓN DE SOBERANÍA POPULAR EN LA TRATADÍSTICA INGLESA; 3 EL PASAJE DE LA CONFEDERACIÓN A LA CONSTITUCIÓN DE UN ESTADO; 4 EL PASAJE DE LA CONSTITUCIÓN DE UN ESTADO A LA ESPECIFICACIÓN DE SUS FACULTADES; 5 EL PROBLEMA DE LA TOMA DE DECISIONES EN MODELOS DUALES; CONCLUSIONES; REFERÊNCIAS.

\section{INTRODUÇÃO}

El problema del constitucionalismo norteamericano fue definido de forma radical a inicios del siglo pasado por Burgess, quien suponía que la ley fundamental tenía que funcionar de una forma dual, es decir, oponiendo dos principios: de un lado el principio de distrobución, división y organización de los poderes, del otro el principio de representación, de asociación y de libertad de los individuos ${ }^{1}$. Pero eso no es todo: suponía que tale principios tenían que regir de forma directa en las diversas formas de aplicación de la ley por parte de la administración, y por ende tener en cuenta las exeperiencias precedentes, sea de los gobiernos, sea de la jurispuredencia, sea de la legislación. En estos términos, la Constitución viene a trazar los principos que rogen a los poderes Legislativo, Ejecutivo y Judicial y reconoce los principales derechos naturales de los ciudadanos, más a través de una síntesis de su practica antecedente, de modo de limitar a la misma practica frente a las dificultades que eventualmente se presenten. Es en ese sentido que el modelo constitucional prevee, por ejemplo, cómo han de substituirsevacantes y la remoción de empleo de los funcionarios culpables de delitos o de abuso de su autoridad: esto solo tiene lugar en cuanto tales eventualidades o hechos ya fueron, previamente, considerados por parte del derecho que los delimita. Tal consideración limitativa hace de la constitución una ley fundamental, cuyo fundamento reside precisamente en una previsión de la práctica jurídica a partir de una serie de principios y prescripciones asumidas de forma antecedente.

Ahora bien, la existencia de una constitución comprende, entonces, ya da por supuesto una autoridad generalmente acatada que permita establecer una decisión del caso resolviendo las cuestiones de la jurisprudencia, que respete las libertades consuetudinarias por la costumbre de una larga practica (de resistencia, de experiencia, de antecedentes, etc.). Se hace evidente

\footnotetext{
${ }^{1}$ BURGESS, John. Political Science and Comparative Constitutional Law. Baker and Taylor Company: New York, 1902. p. 175.
} 
con ello que el modelo adoptado por tal constitución es el tribunal federal y sus fallos judiciales. Sería preciso entonces pasar por la experiencia de la práctica judicial de los tribunales ejemplares (como se comprende el norteamericano) para ir a la letra constitucional en sus artículos, de modo que a sus disposiciones se les agregue, como corolario, los modos de darlas a disposición o usarlas. Pero estas disposiciones no se refieren de forma unívoca y del mismo modo a gobernantes y gobernados, en cuanto la situación fáctica de la sociedad se encuentra en conflicto y las costumbres no se establecieron según la corrección de las reglas de conducta: solo una vez instauradas las formas civiles que suponen los derechos ciudadanos se puede considerar la práctica constitucional como "regla de conducta".

\section{EL VALOR DE LOS ANTECEDENTES Y LOS PRINCICIPIOS CONSTITUCIONALES}

El problema de los antecedentes constitucionales que orientan a sus principios, tal como los formulaba Burgess, es que no se regía de forma directa por una consideración histórica, sino por una comparación de modelos. Ahora bien, como ya señalaba otro teórico constitucionalista norteamericano, Joseph Story en su Commentary of Constitution of the United-States, with a preliminary review of the constitutional history of the Colonies and States, before the adoption of the Constitution, tampoco a nivel del ejercicio del poder se adopta simplemente un modelo de principios fijos, sino que se consideran hechos previstos de forma antecedente. Así, si bien es posible determinar el plan general de las constituciones norteamericanas, la federal y la de sus estados, bajo la división del gobierno en tres ramas o poderes que ya se encontraba en Montesquieu (el Legislativo, el Ejecutivo y el Judicial) no es menos cierto que las líneas de demarcación de los poderes no son estrictamente guardadas en la Constitución federal, porque el presidente tiene algo que hacer con la legislación, y el Senado se mezcla en los nombramientos hechos por el Ejecutivo, de modo que la independencia de lostres departamentos coordinados en el gobierno, supone que no, solo las facultades de cada uno estén clasificadas y definidas, sino especificar los modos en que, procedimentalemente, se puede distinguir cómo no venga uno a invadir o subordinar las funciones de los otros².

\footnotetext{
${ }^{2}$ STORY, Joseph. Commentary of Constitution of the United-States, with a preliminary review of the constitutional history of the Colonies and States, before the adoption of the Constitution. Millard. Boston: Gray and Company, 1833. p. 315-16.
} 
Arendt señalo en su ensayo Sobre la revolución el hecho de que la concesión de los derechos ciudadanos a cualquiera sin importar la clase o la proveniencia del sujeto comprendría en si uno de los elementos determinantes para analizar la radical diferencia de la misma con la de la mayoría de los países de Europa Occidental ${ }^{3}$. De este modo el estatuto del sujeto ciudadano y su lugar frente a la administración a la hora de reclamar o hace valer sus derechos no está determinado en primera instancia por el estatuto social del mismo: aunque en verdad lo está con respecto a sus pares (según las diferencias de clase) pero no frente a la misma administración en un sentido formal. Así, en el caso de Inglaterra, es evidente que nunca puede surgir una cuestión respecto de la Constitucionalidad de una ley del parlamento inglés, porque ese cuerpo está investido con un general y supremo poder legislativo, pero en los Estados Unidos y las constituciones que siguen su modelo, que basan la legitimidad del ejercicio en sus instituciones a partir de una ley fundamental, un conflicto entre el sus distintos órganos de gobierno ( $\mathrm{y}$ a quienes representan) puede plantarse, sobre todo cuando está en juego un problema que concierne a un tercero. Es particularmente ilustrativo lo que Bryce dice a este respecto:

En Inglaterra y en otros muchos estados modernos, no hay diferencia en autoridad entre una ley y otra. Todas son hechas por la legislatura; todas pueden ser modificadas por la legislatura. Lo que se llama en Inglaterra leyes constitucionales, tales como la Magna Carta, la declaración de derechos, la ley de sucesión, las leyes de unión con Escocia e Irlanda, son leyes como cualquiera otra, que pueden ser derogadas por el parlamento en cualquier momento, ni más ni menos, como puede derogarse una ley sobre caminos nacionales, o rebajar los derechos sobre el tabaco... Aquí, por lo tanto, podemos observar dos diferencias capitales entre Inglaterra y los Estados Unidos. Inglaterra ha dejado los contornos, tanto como los detalles de su sistema de gobierno, esparcidos entre una multitud de leyes y de casos. Los Estados Unidos los ha trazado en una comprensiva ley fundamental. Aquélla ha colocado las llamadas leyes constitucionales a merced de su legislatura, que puede abolir cuando lo desee cualquiera institución del reino, la corona, la cámara de los lores, la iglesia establecida, la cámara de los comunes, el mismo parlamento; éstos han colocado toda su constitución fuera del alcance del congreso, proveyendo un método para enmendarla, cuyas dificultades se demuestran con el hecho de que tan rara vez se le ha usado. ${ }^{4}$

Pero esta distinción solo se puede volver competenete si tenemos en cuenta el hecho de que la constitución norteamericana fue formulada a partir de los movimientos que comprendieron a la violencia revolucionaria. La constitución, según Arendt, tenía el cometido, a

\footnotetext{
${ }^{3}$ ARENDT, Hanna. On Revolution. London: Penguin Classics, 1990. p. 141.

${ }^{4}$ BRYCE, James. The American Commonwealth. New York: McMillan and C.0, 1888. p. 160.
} 
la vez, de fijar los términos de la libertad por al que se peleaba, y de reunir y evitar la separación de las diferentes regiones y estados que luchaban por la liberación ${ }^{5}$. Desde allí los problemas que puede llegar a formular la constitución norteamericana difieren radicalmente de aquellos que rigen a las actas inglesas: es más, en cierto punto van dirigidos contra las mismas. Un ejemplo de ello está en el problema del modo de proceder de la jurisprudencia ante los casos: como sabemos, según el sistema norteamericano de constitucionalidad, toda ley del congreso o de la legislatura de un estado puede ser nulificada, si los tribunales juzgan que está en conflicto con su constitución. El problema se plantea porque entra en conflicto la doctrina de la soberanía popular, la legitimación de las autoridades elegidas y la nulificación de la decisión de esas autoridades por parte de otros funcionarios especializados seleccionados por procesos indirectos.

En verdad en el medio de los problemas que se plantea la constitución norteamericana y la cuestión de su origen es evidente la siguiente cuestión: aquella oposición que Burguess señalaba entre la distribución independiente de los poderes y las libertades de los ciudadanos, es en verdad una transposición constitucional y jurídica del problema político que merma en la oposición entre el aparato de gobierno y las formas de ejercicio de la soberanía popular. Así, si bien los problemas políticos derivados del control de constitucionalidad es un tema un poco remanido en el debate constitucional local, intentaremos aportar en este ensayo algunas ideas nacidas del actual debate norteamericano que quedan solapadas en el ámbito latinoamericano y que coadyuvan a enriquecerlo: ¿cómo organizar un proceso que señale de forma fiable aquellas raras ocasiones en que un movimiento político consigue justamente el reconocimiento especial que concede el resultado de la deliberación movilizada en nombre del pueblo? En segundo lugar, surge la cuestión de la legislación ordinaria: ¿cómo crear incentivos para que los cargos elegidos públicamente se impliquen en la deliberación por el bien común a pesar de las presiones de los intereses particulares? En tercer lugar, se plantea el diseño de los mecanismos de preservación: ¿cómo preservar los juicios ponderados del Pueblo movilizado frente a la erosión ilegítima de las decisiones normativas del gobierno normal?

${ }^{5}$ ARENDT, Hanna. On Revolution. London: Penguin Classics, 1990. p. 180. 


\section{EL PROBLEMA DEL ORIGEN DE LA NOCIÓN DE SOBERANÍA POPULAR EN}

\section{LA TRATADÍSTICA INGLESA}

Es preciso comenzar el debate con algunas cuestiones previas relacionadas a los vínculos que se generan entre el soberano, quien quiera que este fuere, y las autoridades de un gobierno. En verdad el problema de la soberanía, sea como fuera planteado supone su depósito en una sede abstracta, en cuyo lugar puede estar o bien un sujeto, o bien una pluralidad. Esta distinción ya se había dado en los conflictos ingleses en torno a la revolución gloriosa al confrontarse el monarca con los miembros del parlamento. Sin duda es ejemplar la resolución que daba Hobbes a aquellos problemas: para este, es esencial separar el concepto de la persona como autoría y actuación: el soberano es el actor que personifica al pueblo garantizando su conservación a través de sus actos, ordenes, mandatos, más sin quedar sujeto al pacto; el pueblo, en cambio, es el autor, quien da la unidad a la voluntad, más cuyos miembros se sujetan a observar las prescripciones del soberano ${ }^{6}$.

De estas atribuciones se podían seguir una seire de dicotomías que atravesaban al pode público: una vez establecida esta transferencia al soberano, sea un individuo o asamblea representante, quedan fijados un conjunto de derechos soberanos: si es una asamblea, se instituye una república, si es un individuo una monarquía que no pueden ser cambiadas. El poder del soberano no puede ser alienado y tiene que mantenerse en su sede: el que rompe el pacto comete una injusticia y debe ser castigado; del mismo modo, el soberano no puede infringir el pacto, ya que este lo sustenta con la fuerza pública; de allí que este ser juez en controversias, pero también con respecto a las opiniones públicas, le concierne hacer la guerra de forma conveniente al exterior y designar sus consejos, y acuñar moneda para sustentar el gasto público; el soberano, además instituye la diferenciación de la propiedad entre las partes y la asegura.

Ahora bien a través de estas dicotomías Hobbes no deja de mantener una constante indivisible: esta consiste en el hecho de que los derechos del soberano son incomunicables e inseparables: si se dividen en Cámaras, entonces de la división surge inmediatamente la discrepancia política y la guerra civil. La soberanía por institución o por adquisición delimita los mismos derechos: el derecho de patria potestas, de vida y de muerte, que se expresa dentro del Estado como castigo, y fuera de él, como guerra.

\footnotetext{
${ }^{6}$ HOBBES, Thomas. Leviatan. New York: Oxford University Press, 1998. p. 98-112.
} 
El problema del carácter "sagrado" y absoluto del poder soberano sin límites es en cierta medida atenuado por la elección de un régimen que acuerde, con mayor probabilidad, el uso de la fuerza con respecto a la racionalidad y no al arbitrio de las pasiones. Esto no afecta a la distinción entre formas de gobierno que, siguiendo el modelo clásico, para Hobbes son tres: monarquía, democracia o aristocracia, y depende de la representación de un individuo o una asamblea. La sucesión tiene que hacerse por palabras expresas: consiste en la transmisión de una eternidad artificial y perenne, no inmortal ni heredada por un linaje. El requisito de la autoridad soberana lo aporta la existencia de una autoridad que disponga del derecho soberano de constreñir por la fuerza de modo que cada uno que transfiere su derecho sea obligado a obedecer, sea libremente, sea por la constricción de la pena. De esta concesión recíproca surge una sociedad democrática con poder soberano no limitado por la ley con respecto a la cual todos están de acuerda, sea explícita o tácitamente una vez que fue transferido el poder de defenderse o derecho natural. Es preciso que esta obediencia sea mantenida sin excepción aún ante una decisión absurda: ahora bien, es en la democracia en la que hay menor probabilidad de una decisión absurda de la mayoría; a la inversa, allí en donde los soberanos son absolutos, estos se cuidan más de evitar la violencia, en cuanto la misma es un signo de absurdidad en las órdenes que emiten. El gobierno tiene como fin, entonces, refrenar el apetito conducido por las pasiones y orientarlo hacia los dictámenes de la razón: el esclavo verdadero no es el sujeto, que se atiene en su conducta a los límites de la razón, sino el que está sujeto al arbitrio de sus propias pasiones y cree tener por ello libre albedrío. Es preciso entonces considerar la diferencia entre sujeción y esclavitud para comprender cómo la formación de un gobierno democrático puede implicar ventajas para la libertad en los límites del Estado. En primer lugar la libertad privada que, limitada por los edictos del soberano es a su vez garantizada por su autoridad: la cantidad de fuerza que cada uno transfiere para la defensa de su cuerpo es precisamente la que queda depositada en común para la protección de cada uno de los miembros del cuerpo social.

Frente a esta doctrina, por así decirlo, dividida, que distingue entre el pueblo y la sede del poder, entre los sujetos y el mandatario de forma tajante, y mediando a través del gobierno, Locke va a establecer una especie de mediación a través de la cual se hace posible romper con la forma clásica establecida por el modelo inglés ${ }^{7}$. Este modelo, en resumidas cuentas, establece a la sociedad civil como la sede del poder, y deriva, a la inversa, una división de poderes entre el ejecutivo, que presenta a la forma del monarca, y el legislativo, que presenta a la forma del pueblo. Ahora bien, en ninguno de los dos modelos ingleses se presenta la importancia radical

${ }^{7}$ LOCKE, John. Two Treatises of Government. New Heaven: Yale University Press, 2003. p. 53-59. 
que vedrá a tener el pode judicial en el modelo noertamericano, como veremos en los siguientes análisis.

\section{EL PASAJE DE LA CONFEDERACIÓN A LA CONSTITUCIÓN DE UN ESTADO}

La preminencia del poder judicial en el derecho constitucional estadounidense no concierne a que este tuviera mayor poder por encima del poder legislativo o el poder judicial: comprende, en cambio, el hecho de que es a través de los juzgados que el ciudadano puede reclamar ante cualquier falta cometida sobre sus derechos. Ahora bien, como lo nota Arendt, el surgimiento de esta formación judicial no se establece inmediatamente con la revolución sino luego del período de guerras civiles al mometo de delimitar las enmiendas constitucionales ${ }^{8}$. Pero los problemas internos ya se habían dado desde los albores de la revolución: en este punto inicial, todos los poderes de gobierno pertenecían a los estados, salvo algunos que, por virtud de un convenio entre aquellos llamado "Pacto de Confederación y Perpetua Unión," se habían cedido al Congreso Continental. Sin embargo, los poderes conferidos al Congreso por el pacto de Confederación eran vagos e ilusorios: eran prácticamente nada porque cuando se confería un poder se negaban los medios de ejercitarlo. No hubo unión efectiva de los estados, ni algo que pudiera llamarse gobierno nacional, hasta que se adoptó la constitución de 1789. Antes de esto, se tenía un congreso consistente en un solo cuerpo de delegados, de modo que todas las votaciones eran tomadas por estados y una mayoría de delegados por un estado decidía del voto de ese estado. Aquello era un débil intento de organizar un gobierno y correspondió a su propósito mientras duró el peligro común de una dominación británica.

En este sentido lo que rigió a la formación del régimen político estadounidense manteniendo la cohesión entre sus miembros fue precisamente la exigencia de excluir a la dominación británica como un tercero en pugna. Ahora bien, cuando esa amenaza dejó de existir por la paz de 1783, el egoísmo y los celos de los estados se intensificaron y amenazaron con romper los débiles lazos que los tenían unidos: en este punto, lor órganos de coalición que darían vigencia al texto constitucional y unidad a las formas de gobierno comienzan a perder poder. El congreso llegó a ser el hazmerreír del país y los mejores hombres evitaban entrar en él; y ello de un modo tal que había contraído deudas para sostener la guerra, y como los estados descuidaban o rehusaban pagar sus cuotas, se protestaron documentos contra el congreso, y éste

8 ARENDT, Hanna. On Revolution. London: Penguin Classics, 1990. p. 230. 
quedó desconceptuado porque no tenía facultades para imponer y cobrar contribuciones. Ahora bien, de esto y de muchas otras cosas semejantes vino la convicción en el ánimo de los estadistas norteamericanos de que era necesaria "una unión más perfecta;" de que debían tener un gobierno nacional al cual se le confiaran todos los poderes generales, especialmente los que afectaban las relaciones con las naciones extranjeras y las relaciones de los estados unos con otros, e incluyendo los que fueran necesarios para la defensa general y el bien público.

Vemos entonces cómo el problema de evitar la división interna entre los estados llevó a la reformulación del texto constitucional que, por otro lado, solo pudo entrar en vigencia luego de la guerra civil y el triunfo de la Unión. No es posible entrar aquí en detalles de los acontecimientos tan intensamente interesantes y de las discusiones que obligaron al fin al pueblo de los estados a conferir con repugnancia al gobierno general un poder nacional adecuado a sus fines. Hanna Arendt, en su ensayo Sobre la revolución establece de forma esquemática el modo en que la formación del constitucionalismo norteamericano vino delimitar un concepto de la republica cuya base no estaba en las naciones que la componían. En verdad esto solo se resuelve luego de las guerras civiles: por otro lado, es preciso notar que Arendt pone el énfasis en el hecho de que sean las formas constitucionales de gobierno las que rigieron, y no las formas europeas de la razón de Estado, en la formación de la práctica constitucional norteamericana. Agamben, sin embargo ha puesto entre paréntesis este segundo postulado, al notar el hecho de que, desde la consolidación de la Unión, Lincoln opero bajo el estado de excepción de forma recurrente. En todo caso, para especificar ambos problemas es importante hacer notar aquí la diferencia entre los poderes del gobierno nacional y los de los estados. Los trece estados originales estaban organizados como estados, y cada uno de ellos había adoptado su constitución antes que la de los Estados Unidos fuera formada y adoptada9. Como sabemos, la constitución de los Estados Unidos fue formada por una convención que se reunió en Filadelfia el 14 de mayo de 1787, y acabó sus labores el 17 de septiembre de ese mismo año. Notemos desde ya que la figura del pueblo tiene un carácter retórico y estratégico determinante para lo que concierne al establecimiento de la unidad supuesta de los estados que, sin el mismo, no tiendrían causa alguna de unificación. Según el uso común en los Estados Unidos, para hacer la constitución de un estado, se debe elegir delegados a una convención por voto popular, cuyo deber es preparar un plan de gobierno. Cuando los delegados han llegado a un acuerdo y han autenticado debidamente el documento, éste se somete al voto directo del pueblo, y cada

\footnotetext{
9 Salvo Connecticut, donde los "Mandatos Fundamentales" de 1639 continuó en vigor como la ley orgánica del estado hasta 1818 y Rhode Island, donde la carta de 1663 estuvo igualmente en vigor hasta 1842, el resto había adoptado el modelo de organización bajo este nuevo tipo, una constitución.
} 
votante deposita una ficha inscrita, "Por la constitución," o "Contra la constitución." Si una mayoría vota por la constitución, entonces ella se convierte en la ley suprema del Estado ${ }^{10}$. El artículo quinto dispone en cuanto a las enmiendas que:

Siempre que las dos terceras partes de ambas Cámaras lo juzguen necesario, el Congreso propondrá enmiendas a esta Constitución, o bien, a solicitud de las legislaturas de los dos tercios de los distintos Estados, convocará una convención con el objeto de que proponga enmiendas, las cuales, en uno y otro caso, poseerán la misma validez que si fueran parte de esta Constitución, desde todos los puntos de vista y para cualesquiera fines, una vez que hayan sido ratificadas por las legislaturas de las tres cuartas partes de los Estados separadamente o por medio de convenciones reunidas en tres cuartos de los mismos, según que el Congreso haya propuesto uno u otro modo de hacer la ratificación... ${ }^{11}$.

El problema de las enmiendas, que en la actualidad tiene un marco excepcional y abocado al caso, solo pueden entenderse por las moficaciones que se preveen con respecto al desenlace de conflictos sociales mayores que precisamente vienen a modificar el estatuto en que se comprende la unidad previa del “pueblo". Así pues, las enmiendas deben someterse a las legislaturas de los estados o a las convenciones como lo resuelva el congreso: pero su auténtica determinación refiere al pueblo y, por ende, a la idea de un pacto social originario, sin el cual, tales modificaciones serían imposibles ${ }^{12}$. Es verdad que el voto para la adopción de la constitución fue, y que el voto para las enmiendas es por estados, en convenciones de estados o en sus legislaturas, y que la entidad de los estados es reconocida de otros diversos modos en la administración del gobierno nacional. Difícilmente podría ser de otro modo: la idea de los estados separatistas residía en considerar a la constitución como un mero pacto entre estados independientes, de que cada estado puede separarse de la unión por cualquiera infracción de las condiciones del pacto, y de que cada estado es juez por sí mismo para decidir si el pacto se ha

\footnotetext{
${ }^{10}$ La legislatura no hace la constitución: es la constitución la que hace la legislatura y aun cuando la convención se haya reunido por virtud de una ley de la legislatura. La idea norteamericana es que las constituciones proceden del pueblo en el ejercicio de su derecho natural de gobernarse a sí mismo, y sólo pueden ser reformadas o derogadas por el pueblo. Cualquiera ley que dé una legislatura o un congreso, la próxima legislatura o el próximo congreso la puede revocar, pero ni la una ni el otro pueden revocar ni infringir una disposición constitucional.

${ }^{11} \mathrm{El}$ poder de enmendar no se extiende a privar a alguno de los estados, sin su consentimiento, de su voto igual en el senado.

12 Debe notarse también que el voto sobre la adopción de la constitución y sobre sus enmiendas es por estados, teniendo cada estado un voto sin atender a su población. Pero aun cuando estas disposiciones hacen la acción popular menos directa de lo que es usual en los estados, y necesariamente reconoce a los estados como entidades para hacer y enmendar la constitución, la idea de que las constituciones proceden del pueblo no por eso se pierde.
} 
violado; sin embargo, esta tesis no tiene apoyo ni en la historia de la adopción, de la constitución ni en los términos de ese documento.

Como se ve el esquema adoptado supone entonces conjugar de forma compleja un aparato de centralización que a la vez, asegure la independencia e los estados, mantenga la determinación unitaria de las representaciones, y distribuya las libertades particulares de forma igualitaria. En un plan de gobierno propuesto a la convención, el Congreso había de tener facultad para convocar las fuerzas de la unión contra cualquier miembro de la unión que dejara de cumplir sus respectivos deberes. La constitución y las leyes de los Estados Unidos toman a cada individuo y tratan con él, no como ciudadano de este o aquel estado, sino como a un ciudadano de los Estados Unidos. En un sentido propiamente constitucional no puede haber separación ni guerra entre un estado y los Estados Unidos, porque ninguna sanción legal puede tener una ordenanza de un estado que rechace la autoridad nacional o que organice una resistencia contra ella. De este modo, se puede entender como lo determinante de la la formación de la constitución norteamericana está en conjugar, de forma triple, la distinción entre la unión general, la independencia de cada estado, y los derechos de cada particular, sin que estas instancias vengan a cruzarse: ahora bien, esta distinción supone una serie de precisiones con respecto a los casos.

\section{EL PASAJE DE LA CONSTITUCIÓN DE UN ESTADO A LA ESPECIFICACIÓN DE SUS FACULTADES}

Tenemos entonces que especificar entonces el modo en que se delimitan los casos específicos a través de los cuales pueden llegar a dividirse, en su ejercicio concreto, las facultades establecidas para el poder central y aquellas respectivas de cada uno de los estados. Como sabemos, el gobierno nacional norteamericano está formado de facultades especificadas o especiales. El Congreso no puede legislar sobre todos los asuntos sino solamente sobre aquellos sometidos a su dirección por la Constitución. Los tribunales de los Estados Unidos, a su vez, no pueden conocer de todos los juicios, sino sólo de aquellos que se refieren a determinados asuntos o personas o que se suscitan entre particulares en los casos especificados por la constitución. Los términos en que está concebido el primer artículo de la constitución son: "Todos los poderes legislativos otorgados en la presente Constitución corresponderán a un Congreso de los Estados Unidos...". Por otra parte, los estados tienen plenos poderes legislativo y 
judicial sobre todos los asuntos, excepto los que han sido encomendados por la constitución de los Estados Unidos al gobierno nacional o que la misma constitución ha prohibido a los estados.

Como vemos, la figura del pueblo, del pacto fundador, y del consentimiento, tienen la función, no solo de unificar en general a las distintas regiones, naciones y estados, sino también de distribuir de forma igualitaria los derechos de cada individuo como ciudadano en general. Ahora bien, a nivel de la delimitación de casos efectivos, el punto determinante está e discernir cuales son las facultades que se atribuyen al gobierno central y cuales son aquellas que conciernen a los estados, La constitución de los Estados Unidos, los tratados internacionales y las leyes del Congreso, cuando éste obra dentro de los límites constitucionales, son superiores y dominan a toda constitución o ley de los estados.

Ahora bien, si estas funciones de conservación general conciernen al poder central, las funciones de desarrollo regional específico parecen ser distribuidas a los estados y sus localidades, de modo que es preciso notar que una larga lista de poderes quedó reservada a los estados. En general, esa lista abraza todos aquellos asuntos que se refieren al gobierno y autoridad locales. La dirección local de los asuntos locales es tan esencial como la dirección nacional de los asuntos nacionales. La enmienda décima de la constitución dice: "Los poderes que la Constitución no delega a los Estados Unidos ni prohíbe a los Estados, queda reservados a los Estados respectivamente o al pueblo." Con ello hay que especificar que, como se ha dicho ya de un modo general, las facultades son delegadas a los Estados Unidos.

\section{$5 \quad$ EL PROBLEMA DE LA TOMA DE DECISIONES EN MODELOS DUALES}

Ahora bien, una vez diferenciados los casos específicos que conciernen a la formación de cada Estado con respecto a al poder central de los Estados Unidos, es preciso pasar a referir, de manera sumaria, el modo en que esto puede repercutir en la toma de decisiones. Los puntos que hasta aquí desarrollamos nos llevan a analizar el meollo del problema desde otra perspectiva: los problemas que genera este dualismo no solo entre el Estado y los estados, sino entre el gobierno respectivo a ellos y la constitución general. Por encima de cualquier otra consideración, una Constitución con base en la soberanía popular busca distinguir entre dos decisiones diferentes que pueden tomarse en una democracia. La primera es una decisión que toma el pueblo; la segunda, la toma su gobierno. Las decisiones tomadas por el pueblo se producen raramente y en unas condiciones constitucionales especiales.

En verdad, como hemos visto, la figura del "pueblo" tiene, mientras el regimen constitucional se encuentra vigente y no se desatan guerras civiles o revoluciones, una función 
jurídica y representativa que no concierne a un agente directo: refiere más bien a la unidad que comprende el consentimiento del pacto, y a su vez a la distribución igual de los derechos sobre los particulares. Ahora bien, es precisamente lo inverso con respecto al gobierno: las decisiones tomadas por el gobierno tienen lugar a diario, y también en circunstancias especiales, pero siempre se refieren a un caso tal o cual. Y lo que es más importante, los cargos clave tienen que responder regularmente ante las urnas: de allí que lo que se ponga en juego en el centro de este debate sea el problema de la nulidad. Ahora bien, si la fuente de legtimidad que permite operar al gobierno por medio de un establecimiento delegado que es confirmado a través del voto en las elecciones, entonces es preciso afirmar que la figura del pueblo tiene una función que la liga directamente al gobierno en su instancia procedimental: y esta no es otra que aquella concerniente la función democrática revindicada por los denominados "monistas". Es posible que determinados controles constitucionales puedan impedir que los vencedores revoquen las siguientes elecciones programadas; es posible que otros estén justificados si consideramos formas más profundas en que unas elecciones normales no satisfacen los ideales de justicia electoral. Si bien estas excepciones pueden tener una gran importancia práctica, los monistas se niegan a dejar que oculten la cuestión principal: cuando el Tribunal Supremo, o cualquier otra instancia, invalida una norma, se resiente de la dificultad de contradecir a la mayoría que ha de ser superada antes de que un buen demócrata pueda expresar su satisfacción respecto a esta acción extraordinaria.

Muchos autores afirman que tal idea de un control democrático que mide, en última instancia el nivel del consentimiento popular sobre la autoridad proviene de la oposición inglesa entre la cámara de los comunes en el parlamento a la monarquía. Desde hace más de un siglo, el Primer Ministro ha ocupado el cargo después de unas elecciones relativamente justas y, excepto en circunstancias verdaderamente excepcionales, la Cámara de los Comunes ha dado un apoyo inquebrantable a las propuestas del gobierno de Su Majestad. Si al pueblo de la Gran Bretaña no le gusta lo que está pasando, le hará regresar a la oposición en las próximas elecciones. Hasta entonces, ni la Cámara de los Lores, ni la reina, ni los tribunales minarán seriamente las decisiones legislativas tomadas por una mayoría de los diputados de la Cámara de los Comunes

Ahora bien, una posición más moderada del monismo tendría que comprendeer, al menos, que la aplicación efectiva del gobierno a los casos supone un margen judicial dado al control de constitucionalidad sobre las operacioes y que no puede resolver se de forma simplemente inmanente al criterio social generalizado. Esto sucede ante todo con los 
conservadores constitucionales como Alexander Bickel $^{13}$, centristas como John Ely ${ }^{14}$, y progresistas como Burgess ${ }^{15}$ han propuesto roles para el Tribunal Supremo que se sitúan en el marco de las premisas monistas. A los efectos que aquí nos interesan, es la cuestión monista, no la proliferación de respuestas a la misma, lo que ha de someterse a un escrutinio crítico. El monista incurre en una petición de principio crucial cuando afirma que el ganador de unas elecciones libres y justas tiene derecho a gobernar con toda la autoridad popular.

Pasamos entonces de una consideración monista de la cuestión de la legitimidad en el ejercicio del gobierno a una forma dualista que comprende en sí mecanismos inmanentes de constrol de constitucionalidad. Una vez que se reconoce el carácter dual del sistema, el Tribunal Supremo aparece bajo una luz diferente. Sin embargo, es evidente que esta pregunta retórica, no hace sino indicar el medio por el cual la despolitización de la ciudadanía delega a los denominados "políticos de profesión" la resolución de los asuntos sociales fundamentales.

\section{CONCLUSIÓN}

Como pudimos ver, aquellas oposiciones generales que el texto constitucional establecía al modo de generar una especie de equilibrio de facultades entre el poder central, los estados y cada ciudadano en particular, a nivel de la aplicación del poder mismo a los casos en cuentra puntos de bifurcación que exceden las codificaciones. Estos puntos conciernen al problema de la toma de decisiones: es inevitable que, a nivel de los procedimientos específicos, se de una bifurcación entre una postura monista que encuentra la fuente de legitimidad del gobierno en el consentimiento popular manifestado por el voto, y una postura dualista que exija el establecimiento de un protocolo de contron de constitucionalidad sobre los agentes gubernamentales. Para mantener la integridad del proceso de producción de normativa de carácter superior, todas las constituciones dualistas tienen que prever que una o más instituciones desempeñen una función conservacionista. Ahora bien, es preciso comprender que la postura dualista no significa simplemente la exigencia de un control judicial indeterminado: refiere mñas bien a la exigencia, de contrapartida, de que el monismo pueda llegar a reafirmarse a través de las formas asociadas de la participación ciudadana. De allí que esto no significa que cualquier decisión particular tomada por el Tribunal Supremo actual pueda justificarse en un sentido conservacionista. Pero, ante todo, es preciso afirmar que no es ni (1)

\footnotetext{
${ }^{13}$ BICKEL, Alexander. The Morality of Consent. New Heaven: Yale University Press, 1975. p. 90.

${ }^{14}$ ELY, John. Democracy and Distrust. Cambridge: Harvard University Press, 1980. p. 160.

15 BURGESS, John. Political Science and Comparative Constitutional Law. New York: Baker and Taylor Company, 1902. p. 204.
} 
el acto gubernamental legtimado pro consenso, ni (2) el acto judicial controlador del gobierno lo que delimita el problema, sino el modo y el nivel de participación social extra-protocolar y los medios que se dispongan hacia ello lo que puede establecer un ejercicio efectivo de la democracia.

\section{REFERENCIAS}

ARENDT, Hanna. On Revolution. London: Penguin Classics, 1990.

BICKEL, Alexander. The Morality of Consent. New Heaven: Yale University Press, 1975.

BRYCE, James. The American Commonwealth. New York: McMillan and C.0, 1888.

BURGESS, John. Political Science and Comparative Constitutional Law. New York: Baker and Taylor Company, 1902.

ELY, John. Democracy and Distrust. Cambridge: Harvard University Press, 1980.

HOBBES, Thomas. Leviatan. New York: Oxford University Press, 1998.

LOCKE, John. Two Treatises of Government. New Heaven: Yale University Press, 2003.

STORY, Joseph. Commentary of Constitution of the United-States: with a preliminary review of the constitutional history of the Colonies and States, before the adoption of the Constitution, Millard. Boston: Gray and Company, 1833.

ARTIGO CONVIDADO / Publicado em 10.05.2019

\section{COMO FAZER REFERÊNCIA AO ARTIGO (ABNT):}

CONTRERAS, Claudio Anibal. Ensayo sobre la nulificación de la ley en el constitucionalismo norteamericano: tensiones a partir del monismo y dualismo democrático. Revista Eletrônica do Curso de Direito da UFSM, Santa Maria, RS, v. 14, n. 1, e38097, jan./abr. 2019. ISSN 1981-3694. DOI: http://dx.doi.org/10.5902/1981369438097. Disponível em: https://periodicos.ufsm.br/revistadireito/article/view/38097 Acesso em: dia mês. ano.

Direitos autorais 2019 Revista Eletrônica do Curso de Direito da UFSM

Editores responsáveis: Rafael Santos de Oliveira e Angela Araujo da Silveira Espindola

Este obra está licenciado com uma Licença Creative Commons Atribuição-NãoComercial-SemDerivações 4.0 Internacional.

\section{SOBRE O AUTOR}

\section{CLAUDIO ANIBAL CONTRERAS}

Abogado de la Universidad Nacional de La Plata. Doctor en Ciencias Jurídicas, Universidad Nacional de la Plata. Prof. Titular de Derecho Político de la Universidad del Salvador y de la Universidad Nacional del Noroeste de la Provincia de Buenos Aires, UNNOBA. 